\title{
One Region's Response: The Emergence Of Hispanic Workers In Appalachia
}

Adam Crawford, (E-mail: accraw02@Morehead-st.edu), Morehead State University Adrianne Meade, (E-mail:axmead01@ Morehead-st.edu), Morehead State University Dr. Shane Spiller, (E-mail: S.Spiller@ Morehead-st.edu), Morehead State University Charles Stamper,(E-mail: cdstam02@ Morehead-st.edu), Morehead State University

\begin{abstract}
Surveys were conducted assessing level of preparedness of businesses in Eastern Kentucky for the coming wave of Hispanic immigration. Information was summarized for businesses that have not employed Hispanic workers in the past, including a general overview of the cultural and language barriers providing guidelines to ease the transition. Specific guidelines were accumulated regarding general cultural differences and language problems. The information has been organized into four areas containing both general and specific concepts.
\end{abstract}

\section{Introduction}

Today's businesses will soon be faced with a worker crisis, which will ultimately affect every American leading to the decrease in their standard of living. By the year 2010, the U.S. Department of Labor, Bureau of Labor Statistics forecasts the need for workers in total will increase by $15.2 \%$ or 22,160,141 additional workers. (data.bls.gov). Where will American businesses find these workers? Current population trends indicate that American born workers, who will be turning $20-24$ by 2010 and available to enter the workforce, is $21,151,000$. Assuming the projected 20-24 year old persons all enter the workforce, although highly unlikely, the U.S. will still be faced with a worker shortfall. Baby boomers will then be of retirement age, demanding more services unable or not willing to contribute to production. As has been highly publicized in the press and substantiated by the 2000 Census, the U.S. demand for more workers is being met by foreigners, of which the majority, are of Hispanic origin.

Because of their geographic location providing easy access, states such as Texas, California and Florida have always had substantial Hispanic populations. Due to the greater demand for workers in the U.S. and increased poverty in their home countries, it is estimated that the Hispanic worker could be present in every state, in some areas for the first time. While some Hispanic workers may not maintain full time residency, following the trends seen in California's migrant farm workers, more and more Hispanic workers are staying year round, adopting the U.S. as their new home. (Manning 2000)

Kentucky residents have witnessed a dramatic upsurge in its Hispanic population in the last ten years. Lured here initially with jobs in the tobacco and the horse industries, other businesses seeing the potential, have tapped into this labor pool. Hispanics represent the fastest growing segment of Kentucky's population, with a record number of 60,000 by the U.S. 2000 Census. Local figures, however, place the number much higher somewhere between 100,000 and 135,000. The county with the highest concentration is Jefferson County, encompassing the greater Louisville area. According to the state Department of Agriculture, Hispanics make up about 80 percent of Kentucky's 25,000 tobacco workers. (AP, March 3, 2003) In response, local and state governments have scrambled to provide services. The Lexington Police force has initiated a nationally recognized cultural sensitivity program actually sending some of its officers to Mexico. Because Kentucky's student Hispanic population has doubled in the last five years, the federal government has provided $\$ 622,000$ in 2002 to help pay for bilingual education. The integration of workers from a different culture always presents challenges to any organization, although the impact 
on rural businesses in this case is unprecedented for this generation. The urban regions of the state have larger financial resources at their disposal and have been able to, on a limited basis, address the demands for the changing workforce. As the Hispanic immigration wave pushes deeper into the rural areas of Kentucky, the limited resources of the local governments will force local businesses to shoulder more of the assimilation costs than their urban counterparts. In response to this situation, three objectives will be addressed in this paper. The first objective is to review U.S. history and examine previous immigration waves, identifying similarities to the current Hispanic immigrant explosion. This will isolate business organizational issues and challenges and how they have been addressed in the past. Analysis of past solutions and the degree of success each achieved will also be considered. Secondly, we define the current and future Hispanic worker environment in the Eastern and Central Kentucky region. To facilitate this objective, a questionnaire was developed and administered to thirty Eastern Kentucky organizations. The results of the questionnaire will provide a general perspective as to the degree of readiness rural businesses have in response to the expected influx of Hispanic workers. Finally, both general and specific reference information regarding Hispanic culture is provided. The latter information was obtained through questionnaires and interviews with Americans who have an extensive knowledge and understanding of Hispanic culture, newspaper and magazine articles, and governmental reports. This reference information, while not all-inclusive, does provide a framework to understanding and appreciating the cultural differences of the Hispanic worker.

\section{Historical Perspective of Immigration}

As defined by the U.S. Census, "Hispanic: A person of Mexican, Puerto Rican, Cuban, Central or South American or other Spanish culture or origin, regardless of race". (www.census.gov) This definition of Hispanic will be used throughout this paper. The influx of Hispanic workers currently being experienced by the United States is only the most recent of many immigration waves whose origins are from all parts of the globe. American Indians thought to be the first settlers of this land witnessed the initial colonization of the United States by British and Western European immigrations. This was quickly followed by the importation of the African slaves, establishing an on-going pattern of importing workers to perform manual and unskilled labor. As each wave arrived, there were many barriers to assimilation with the existing general population. Within this context, an examination of several of these waves will be conducted to document the life cycle of immigrant assimilation identifying tactics, which either eased or impeded assimilation.

The Irish: It is estimated that over 43 million Americans can trace their ancestry back to Ireland. The Irish were the largest group to enter the United States and can be found in every state of the union, in both rural and metropolitan areas. Historians categorize the immigration in three waves beginning in the 1700s. The first and second wave of Irish immigrant's initial destination was Philadelphia. Most of the Irish were indentured servants, unskilled labor. The reason for emigrating was primarily for employment and religious freedom. The third wave of Irish came as a result of an English ban on Irish exports coupled with the Great Potato Famine in 1845, which acted as catalysts, ejecting the Irish to America. During the years between 1815 and 1845, roughly one third of the immigrants to the U.S. were Irish. Like the previous two waves, the majority was unskilled, usually young and single, coming to America for employment. During this period, there was a great demand for cheap labor to build the emerging infrastructure of railways, canals and roads, and recruits were aggressively sought after. Unlike the first two waves, the third wave of Irish immigrants made their way first to New York City and Boston. By 1847, a third of Boston's population, or 37,000, were of Irish descent. (Ashabranner, 1993) Irish immigration later spread west to the Appalachia region, where today more than ten percent still claim Irish ancestry. In spite of the initial assimilation difficulties of language obstacles, little education and economic resources, enduring a suspicious and sometimes hostile general population, the Irish overcame the barriers, contributing to the creation of the United States. In a little over 100 years, John F. Kennedy would become the first Irish Catholic president, a far cry from the "No Irish Need Apply" mentality his father faced.

Chinese Immigration: The major immigration to the United States from China began in the middle of the 19th Century as the American West was being settled. While some Chinese were lured to the U.S. in pursuit of quick wealth from the California gold fields, others sought more traditional professions such as starting their own factories. The advanced Chinese farming techniques along with thousands of migrant agricultural laborers combined to allow the new western states to become more self-sufficient in food production. Chinese workers also quickly filled the worker void in the South following the Civil War by quickly taking up the labor shortage caused by the 
exodus of former slaves. Central Pacific Railroad hired nearly 15,000 Chinese as it stretched into the western frontier, constructing the transcontinental railroad. As the Chinese population grew, public fear and ignorance, postCivil War depression, and the belief immigrants held too many jobs combined to create a hostile environment in the United States. Chinatowns were formed in virtually every major U.S. city, which contained eighty percent of the Chinese immigrant population by the early twentieth century. Residing in these communities, Chinese culture and language was maintained, easing day-to-day activities for the new immigrants but isolating them from the general population. In 1882, Congress passed the Chinese Exclusion Act, which completely prevented Chinese without family already in the U.S. from entering the country, thus effectively halting all immigration. (Ailf, 2000) The law serves as the first in U.S. history to ban a specific racial group from entering America and was not repealed until 1943. Unlike the Irish who can be found in both rural and metropolitan areas, the American-born Chinese descendants for the most part have remained in the larger metropolitan cities, maintaining their Chinese language and culture in various "Chinatowns". (Lee, 1965)

Both the Irish and Chinese experienced a similar path of assimilation. The immigration wave began with primarily young males, seeking low-skilled positions, who did not necessarily intend on permanently relocating to the United States, but instead to improve their fortunes and send money back to their country of origin. The establishment of communities populated with families followed this. Like the Irish, the establishment of cohesive supporting communities provided the stability the Chinese needed to create education opportunities and the development of political clout, which eased discrimination and lowered barriers.

\section{Twenty-first Century Immigration - Hispanic Arrival}

The United States has had a long history of utilizing both legal and illegal Hispanic workers, particularly in California and the Southwest, for use in the agricultural sector. The degree of usage has exploded in the last few decades. For example, the United States admitted 297, 000 legal immigrants and the 1,800 Border Patrol agents caught 110,000 deportable aliens, 50 percent Mexicans, in 1965. Twenty years later, 562,000 immigrants were admitted and 70,000 refugees. The Border Patrol was increased to 3,500 and deported 1.3 million aliens, over 90 percent Mexican. (Reference Figure 1)

Illegal alien workers from Mexico, Latin America, and Asia enlarged their foothold in low paying jobs in the 1960s and early 1970s in regions heavily affected by immigration. As is still true today, some of the workers would stay in the U.S. only long enough to accumulate a set amount of wealth and return to their own nation. Others, however, chose to remain in the U.S., opening restaurants or garment shops. Others sought employment outside the agricultural industry, settling on the entry-level positions of the hotels, factories and service organizations in major urban areas.

In California, the Southwest, and a growing number of Midwestern cities, as American workers quit lowwage jobs in pursuit of higher-wage jobs, their replacements were drawn increasingly from villages in bordering Mexico. Small businesses that had suffered from the high turnover of American workers soon realized they could enjoy a reliable workforce like their counterparts in mainstream businesses utilizing illegal immigrant workers but without raising wages or improving quality of work life standards.

The low-cost illegal immigrant workers hired and supervised by ethnic foremen were a welcome relief for the often-shaky businesses that depended on them. Manufacturers in high-cost Los Angeles capitalized on the seemingly unlimited supply of appreciative minimum-wage workers. Close supervision could address quality issues and training was often completed in a single day. In the same way, the restaurant and hotel industries profited by offering its customers superior backroom service without increasing its production costs due to the loyalty and dependability of illegal immigrants, more so than the mixed crews of Americans they replaced. (Martin, 1986) 
Figure 1. Number of Mexican Immigrants

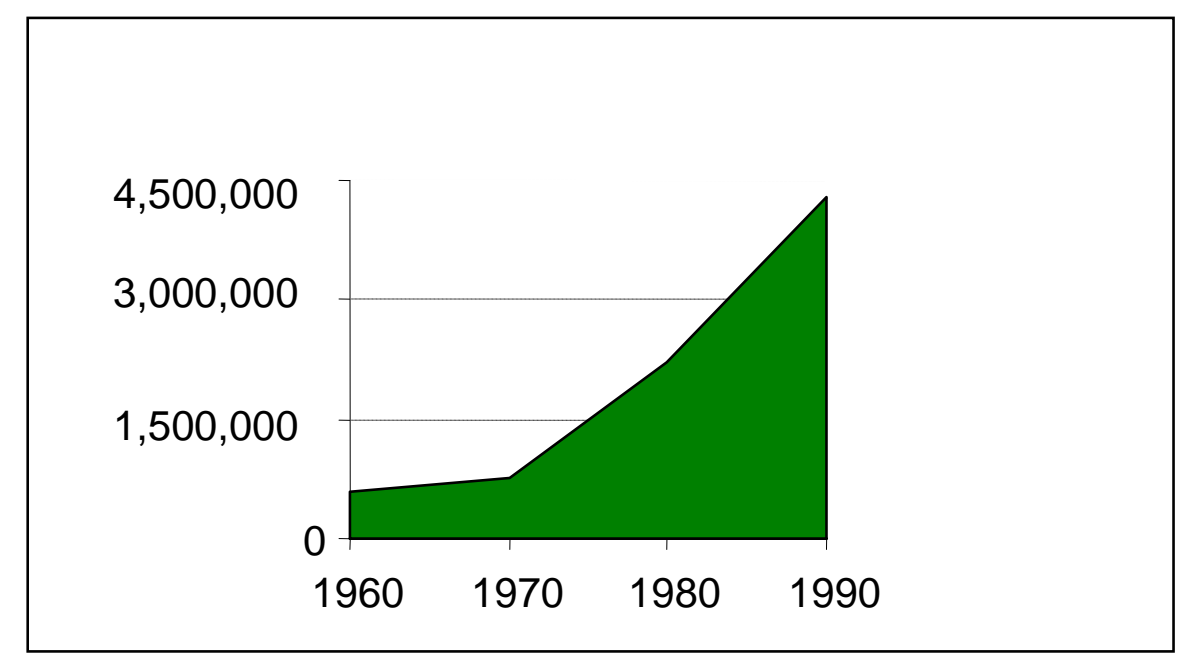

Source: U.S. Bureau of the Census

The Bracero program, which began August 4, 1942, had provided Southwestern agriculture with temporary Mexican farm workers each year ended in 1964. Over the course of the program, more than 4 million Mexican farm laborers came to work the fields of this nation when their own country was too impoverished to provide the workers with a livable wage. While the Braceros enabled American agriculture to become the most productive on the planet, their working conditions were miserable and likened to legalized slavery. (farmworkers.org ) The current Hispanic worker expansion can be traced to the mid-1960s when immigration policy began to change. In 1965 legislative changes abolishing the national immigrant quotas as specified in the Immigration and Nationality Act was replaced with a system of uniform national numerical ceilings that favored the admission of relatives of U.S. residents.

An alternative system evolved to attract Hispanic workers to the U.S. to replace the defunct Bracero Program of the 40s, 50s and early 60s. Recruitment was initiated and maintained by the establishment of an informal network, which provides information, and at times, financing for a trip to the employment location in the United States. Recruitment of foreign workers is an established American practice, dating back to the earliest colonial times. These networks can expand or mature, providing the immigrant worker with information regarding other better paying jobs, away from the traditional agricultural industries. This transition from the farm to the factory has been accomplished in as little as five years. But some networks continue to feed the demand for cheap labor needed in the agricultural sector, using residents from the same village year after year. Field research has shown there is a growing trend of the former, with immigrant workers going directly into urban areas. (Martin, 1986)

But employment has not always brought economic freedom for these workers. A study released in August 1999 by the California Senate found that Hispanic workers in that state lag far behind all other groups in wages and educational attainment, apparent even in the third generation. (Fletcher, 1999) Immigrants are a large and growing factor in the stubborn level of poverty seen in the United States over the past two decades because newcomers to the country are more likely to be poor and remain longer than in the past. The Center for Immigration Studies says the number of impoverished people in the nation's immigrant-headed households nearly tripled from 2.7 million in 1979 to 7.7 million in 1997. During that same period, the number of poor households headed by immigrants increased by 123 percent while the number of immigrant households increased by 68 percent. The share of immigrants living in poverty rose from 15.5 percent to 21.8 percent; a change that some analysts say holds troubling implications for the nation's future. About 12 percent of the nation's native-born population lives in poverty, a figure that has changed little in 20 years. (Fletcher, 1999) 
Each wave of immigrants has a higher poverty rate, and a much larger share of their children will grow up in poverty. Immigrants are more likely to be poor because they have higher levels of unemployment, have lower education levels and have larger families than native-born families, as reported by the Center for Immigration Studies, a Washington-based research group released September 2, 1999. Information compiled by both the 1980 and 1990 census, as well as the March 1998 Current Population Survey, provided the basis for the report. (Fletcher, 1999)

Though faced with these challenges, the number of Hispanic immigrants living in the United States has almost tripled since 1970, as is shown in Figure 2, dramatically altering the nation's demographic and social mix, because the vast majority of current immigrants are either Hispanic or Asian. Overall, immigrants now account for nearly 10 percent of the nation's residents, the highest level since the 1920s. About one in four Californians and one in three residents of New York are foreign-born. If current levels of immigration remain in place, an estimated 10 million new immigrants will settle in the United States within the next decade according to the Center for Immigration Studies.

Figure 2 Number of Hispanic Immigrants

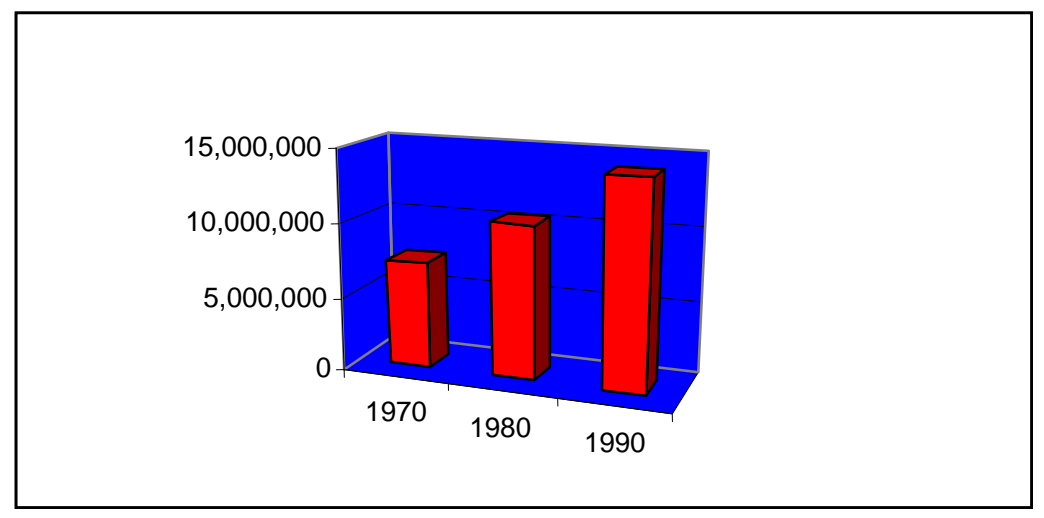

Source: U.S. Bureau of the Census

Many advocates credit immigrants with filling jobs that few others want, revitalizing previously neglected city neighborhoods from New York to Los Angeles and engendering a level of ambition and enterprise often unmatched by native-born residents. Others see high levels of immigration as a burden the country can no longer bear. This negative perspective has accompanied each new wave of immigration as exemplified in the discussion regarding the Irish and Chinese immigration waves presented earlier. Barriers to acceptance include language, education levels and cultural differences. In response to these barriers, Hispanic communities have been created in most urban U.S. areas. While the rapid Hispanic expansion has increased the size of established Hispanic communities, evidence suggests that there is also an expansion into new areas of the country, primarily rural. The following section examines the current impact and future considerations to an increasing Hispanic workforce within Eastern Kentucky.

\section{Eastern Kentucky Businesses' Response to Hispanic Workers}

While the majority of Hispanic workers residing in the Bluegrass state are concentrated in the larger urban areas of Louisville and Lexington, the more rural areas have also seen an increase in Hispanic workers. Typically, they are found providing physical, unskilled labor for jobs with low pay. To determine current business practice regarding Hispanic workers, a short questionnaire was developed and administered to thirty of the more rural Eastern Kentucky businesses. The objective was to evaluate current business practices regarding the hiring of Hispanic workers and planned future changes. 
Thirty surveys were conducted, representing a wide variety of industries. The questionnaire was organized into three distinct sections: business respondent demographic results; current business practices; and future changes planned to accommodate incoming Hispanic workers. Each section is analyzed below.

\section{Section A - Business Respondent Demographic Results}

Overall, the respondents represented a varied cross-section of Eastern Kentucky employers. The agriculture, education, utility, manufacturing, professional, medical, service and retail industries were represented. Agriculture represented seven percent of the respondent population, as did education respondents; manufacturing, utility and professional made up ten percent each; thirteen percent of the respondents considered themselves in the medical sector; twenty percent were service oriented and the remaining twenty-three percent were in retail.

Most of the respondents were from well, established businesses as indicated in the graph below (Figure 3). The majority of respondents had been in operation more than ten years.

Respondents indicated their businesses location in the following Kentucky counties: Boyd, Greenup, Lawrence, Rowan, Montgomery, Fayette, and Jefferson. Sixty-seven percent of the respondents were clustered in three locations located in the northeastern section of Kentucky: thirty percent from Mt. Sterling, (Montgomery County population 23,042), twenty-seven percent from Ashland, (Boyd County population 49,727) and thirteen percent were from Morehead, (Rowan County population 22,174). One respondent listed its location in Louisville Jefferson County the largest urban area whose population is 629,910 . The smallest city location was Louisa, (Lawrence County population 15,722). (quickfacts.census.gov)

Figure 3. Number of Years Respondents in Operation

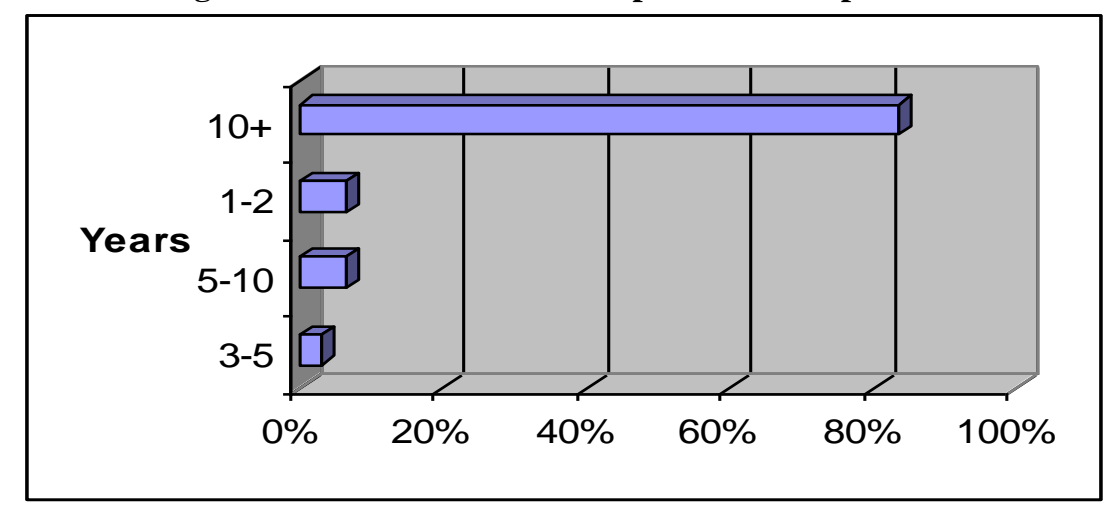

The service or customer areas of the questionnaire respondents were well distributed. On either end of the spectrum, seven percent of the respondents cited a global service area, while seven percent cited a local area. Thirty-three percent claimed to have a statewide service area or twenty-five mile radius. Thirty percent had a one hundred mile radius and twenty-three percent considered their service area to be national.

\section{Section B - Current Business Practices and Policies}

Most of the respondents answered in a similar manner. Below is a summarization of current business practices.

Most companies surveyed had few to no Hispanic employees. The exception, two respondents from the agriculture sector, whose workforces were over fifty percent Hispanic. 
- $\quad$ Most Hispanic workers in the area were found in manual labor jobs (farming, cleaning, etc.), unskilled labor class.

- $\quad$ The number one problem that managers found in employing Hispanics was the communication problem. However, they did feel that this problem would decrease over time as a result of increased educational levels of the Hispanic workers and the availability of managers trained at college and university bilingual programs.

- $\quad$ None of the respondents identified specific cultural traits, suggesting either ignorance of the differences and their potential for workplace miscommunication and inefficiencies or else unconditional acceptance of the differences.

Most managers thought that the level of education and the number of managerial positions held by Hispanics would increase in the future. It was interesting to note that many businesses expressed an interest in hiring Hispanic workers. These were primarily service sector organizations such as the medical/health fields, real estate, and tax preparation. Examples of comments made by some of the respondents are presented below.

- Tax preparation firms seek Hispanic employees to service the ever growing Hispanic cliental. With language being the greatest barrier to efficiency and accuracy, a bilingual tax preparer could provide the firm the required skills to accommodate this emerging market segment. Incentives such as free or discounted courses are being offered to attract the Hispanic preparer. The course, 12 weeks in length for an entry-level preparer, has gained the attention of many Hispanics (low-entry barrier) and enrollment has increased.

- $\quad$ Mental health centers are actively seeking Hispanic employees. The benefits to the consumer in the public health services are very high. The language barrier is especially troublesome in the treatment of mental health illnesses as well as overcoming the cultural bias Hispanics frequently have towards mental illness. While recruitment is ongoing, barriers of entry into the field are very high (master's degree), leaving positions continuously available in anticipation of the benefits of a diverse staff.

- The real estate companies surveyed indicated a strong desire to hire Hispanic employees. The language barrier has left the Hispanic population underserved in this industry, creating sales opportunities, which have not gone unnoticed by area brokers.

\section{Section C - Business Future Plans for Hispanic Worker}

The majority of businesses interviewed did not have any future plans to accommodate the emerging Hispanic worker. Though most agreed that they envisioned future Hispanic hires, no formal plans have been initiated. These results were not unexpected because so few Hispanic workers are actually in the region today. Not only will organizations be hiring more Hispanic workers in the future, more customers will also be Hispanic. Understanding and appreciating the culture will be necessary in order to remain competitive. The last section of this paper addresses the issue of incorporating the Hispanic worker using some specific guidelines.

America's most recent immigration wave has not bypassed the Eastern Kentucky region. Though slow at first, many small towns in Eastern Kentucky are beginning to notice the Hispanic presence. Initially seen in the agricultural and horse industry, Hispanic workers are quickly filling the void in the labor markets created from an aging labor pool. As noted by Ron Crouch, a demographer and director of Kentucky's State Data Center, the median age of the Hispanic is 25 while the median age of the non-Hispanic white is 39 and black median age is 30 . (AP, March 3, 2003) The large metropolitan areas, such as Lexington and Louisville, because of the larger local government budgets, have already implemented programs to aid Hispanics in assimilation. Programs such as Lexington Hispanic Task Force appointed by former Mayer Pam Miller in 1998, whose overall goal is to identify information needs of Hispanic residents, employers, service providers and provide recommendations to the mayor regarding these issues were essential. This provided a framework for response and support for the Hispanic community in the Lexington - Fayette County, Kentucky area. The more rural and less affluent communities will be unable to provide this assistance. More of the burden will be shouldered by local businesses, either in a formal or informal manner. The following discussion keys in on some specific areas of concern together with viable solutions that organizations may adapt to improve this growing segment of the workforce. 


\section{- $\quad$ Supplemental Training for the Hispanic Worker:}

a) In a recent survey of Eastern Kentucky businesses, language was cited as the primary barrier for Hispanic workers. Language classes for new Hispanic workers not proficient in English are an obvious solution. The Hispanic worker can be trained in a relatively simple course approach known as ESL, or English as a Second Language. This program can be used to teach 75-100 jobrelated words or phrases, which drastically improves productivity and is not cost prohibitive.

b) Organizations should also provide written information, such as handbooks and company policies in Spanish. This includes safety training also. Many of the Hispanic workers do not have an appreciation of OSHA and safety rules in place by law in this country.

c) Another aspect of American employment that is not common to the Hispanic worker's experience is employment benefits. The concepts and benefits of payroll deductions and direct deposit may be alien to them. This lack of experience also carries over into the Hispanic worker's understanding of other benefits, such as health insurance, requiring additional explanations.

d) Assistance in setting up bank accounts would be a great benefit. Hispanics are not experienced in using formal financial institutions for their paychecks, being more comfortable using cash.

\section{- Awareness Training for Managers and Coworkers:}

a) It would be beneficial for managers and English speaking coworkers to be aware of some basic Spanish words not only to ease frustrating verbal communication problems but also for safety concerns. Tone of voice used for verbal communication should be slower not louder when addressing the Hispanic worker. Speaking slowly and in common English helps people with limited English to understand, according to Kara McClure, president of PeopleWorks, a human resources consulting firm.

b) Managers should encourage questions and poll for understanding. According to Carol Hastings, co-owner of Corte Hipana, a Santa Monica, California, based company which offers Spanishwritten training materials, most newly arrived Hispanic workers need to be assured there is no punishment for requesting clarification. The fear of being fired or pride may prevent new Hispanic workers from asking questions. This could have dire legal consequences in some situations, especially safety issues.

c) Use of slang, jargon and even sports analogies, maybe misunderstood by the Hispanic worker, should be avoided. For example, "cover all bases" or "off the top of my head" could be taken in a literal sense.

d) Communication can also be non-verbal, as in personal space and body language. Misinterpretation of body stance is common to the uninformed. Because of their close-knit culture, Hispanics generally will stand closer than their typical American counterpart. People in the United States prefer to have a five-foot distance when conversing and may feel threatened or uncomfortable when their space is "invaded." It is not uncommon for some female Hispanic workers to avoid direct eye contact with their supervisors, a sign of respect.

e) The American attitude tends to separate the workplace from home life. The Hispanic culture, which is highly family-oriented, may be inclined to commingle work and family, leading many Hispanics to consider Americans cold and impolite.

\section{- Organizational Policy Awareness}

a) It is important that organizations be aware of the current law and possible implications. For example, on September 19, 2000, the Court System awarded EEOC \$700,000 for Hispanic workers, who by company policy were not allowed to speak Spanish while at the workplace.

b) It is the organization's responsibility to provide all workers a safe environment and safety training. While OSHA is now producing safety literature in Spanish also, not all Hispanic workers have the educational background to read the Spanish versions. Liability issues such as sexual harassment 
policy and job safety might be better left up to either a professional translator or have the material written in clear, generic Spanish.

c) Another circumstance that should be closely monitored is the use of bilingual employees as translators. Hispanic workers can be from a variety of locations, each using a unique dialect which might limit the degree of understanding. It is also difficult to actually verify verbal translated communication in the event of a lawsuit.

Table 1 contains a list of sites, providing more insight to the successful integration of the Hispanic worker into the work atmosphere. The authors of these sites come from a variety of backgrounds, including academia, medical, local government planning commissions, etc. While the information contained in the majority of those sites listed can be applied in most business environments, some have more specific applications and are indicated as such.

\section{Conclusion}

The United States has always depended on the inexpensive labor that foreign workers and immigrants have provided, fueling the economy, raising the standard of living. In return, the workers were provided employment and the opportunity for advancement for themselves or their children. These immigrants and foreign workers faced several barriers to assimilation, including language problems, cultural and educational differences, and political inequities that have lead to blatant discrimination policies in the past. To overcome these barriers, ethnic communities initially were formed primarily in large urban areas. Some immigrant groups, such as the Chinese, have remained for most part concentrated into these original communities. Other groups, such as the Irish, are more evenly distributed throughout the United States. This generation is witnessing a new wave of immigrants, the majority being Hispanic. While the use of migrant Hispanic workers has been a long established practice in the Southwest and California, the rapid increase in Hispanic workers beginning in the 1990s up to the current day has precipitated their presence in other non-traditional areas, such as Appalachia. The focus of this paper was twofold. The first was to examine the relatively new presence of a Hispanic workforce in the Appalachia region, specifically in Northeastern Kentucky from a business perspective; the second was to provide general guidelines and references to assist businesses to prepare to employ Hispanic workers. Questionnaires were used to accumulate business response regarding current and future attitudes toward Hispanic workers. Results of these queries indicated that most businesses were not making specific preparations for the Hispanic workers though all organizations surveyed forecast employing this workforce in the near future. Not surprisingly, the number one issue organizations surveyed had with hiring Hispanic worker centered on the language differences. The lack of preparedness and communication concerns became the starting point of the second issue, which was to address these concerns. While the language differences would remain the greatest barrier, other aspects of effective communication, including cultural differences have been examined. General guidelines to assist businesses in accommodating the Hispanic worker were presented in three categories: supplemental training for the Hispanic worker; awareness training for managers and coworkers; and organizational policy awareness. Strategies for training Hispanic workers in ESL (English as a Second Language); providing safety and organizational policies in generic Spanish; and assistance in negotiating the United States banking process would be very beneficial. Cultural sensitivity awareness for management is essential. Some suggestions to be considered are: management and coworkers develop a very limited Spanish vocabulary to address safety concerns; consideration in word choice, limiting slang terms; an understanding of the non-verbal communication such as body language differences. Organizational policy awareness was also examined. The use of bilingual coworkers as interpreters should be used with caution due to the different dialects; familiarity of EEOC laws and how it relates to Hispanic workers is important; and finally safety concerns were addressed. A table of web sites for more in-depth discussion on these topics completes the discussion, providing organizations, even those with even limited resources, a foundation to build an indoctrination program for the Hispanic worker. 
Table 1 Helpful Web Sites

\begin{tabular}{|c|c|c|}
\hline Web Address & Category & Description \\
\hline http://www.charlotteworks.org/clbpositionpaper.PDF & General & Cultural Diversity \\
\hline http://diversity.netscape.monster.com/articles/understood/ & General & Language Barriers \\
\hline http:ohioline.osu.edu/hyg-fact/5000/5237.html & General & Cultural Diversity \\
\hline http://www.omhrc.gov/haa/HAA2pg/AboutHAA1a.html & General & Cultural Diversity \\
\hline http://www.naschools.net/teachers/hispanic\%20immigrants.html & General & Hispanic Perspective on US life \\
\hline http://www.lincolnu.edu/ diverse/pollock/latino/latino.html & General & Hispanic Perspective on US life \\
\hline http://www.cortehispana.com & General & Legal Aspects \\
\hline http://www.osha.gov/as/opa/spanish/index.html & General & Legal and Safety Aspects \\
\hline http://aolcom.factmonster.com/spot/hhmcensus1.html & General & Current Hispanic Statistics \\
\hline $\begin{array}{l}\text { http://xpedio02.childrenshc.org/stellent/groups/public } \\
\text { /@xcp/@web/@integrativemed/documents/ } \\
\text { 'policyreferenceprocedure/web009309.asp }\end{array}$ & Medical & Cultural Diversity \& Patient Care \\
\hline http://www.emscmn.org/newsletters/summer2002.pdf & Medical & Cultural Diversity \& Patient Care \\
\hline http://www.emscmn.org/newsletters/summer2001.pdf & Medical & Cultural Diversity \& Patient Care \\
\hline http://ohioline.osu.edu/flr-fact/0001.html & Agricultural & OH Migrant Worker Camp \\
\hline
\end{tabular}

\section{References}

1. Associated Press, (2003, March 3). P, The Madison Courier, Madison Indiana, Monday, March 3, 2003, p A10

2. $\quad$ Ashabranner, Brent. (1993). Still a Nation of Immigrants. New York: Cobblehill Books.

3. Campbell J. Gibson and Emily Lennon. (Feb. 1999) "Historical Census Statistics on the Foreign-born Population of the United States: 1850-1990: POPULATION DIVISION WORKING PAPER NO. 29" Population Division of the U.S. Bureau of the Census.

4. $\quad$ Lee, Calvin. (1965) . Chinatown U.S.A. New York: Doubleday \&Company.

5. Martin, Phillip (Jan. 1986). "Illegal Immigration and the Colonization of the American Labor Market: CIS Paper \#1" Center for Immigration Studies.

6. Fletcher, Michael A. (1999, 2 September). Immigrants' Growing Role in U.S. Poverty Cited. Washington Post, p A2.

7. Manning, Robert. (Mar. 2000). "Five Years After NAFTA: Rhetoric and Reality of Mexican Immigration in the 21 st Century" Center for Immigration Studies.

8. http://www.lfucg.com/Mayor/HLTFProcess.asp

9. http:/www.ailf.org/Chinese Immigration (2000). American Immigration Law Foundation

10. http://www.census.gov/population/projections/nation/summary/np-t.txt

11. http://quickfacts.census.gov/qfd/states/21/21127.html

12. http://data.bls.gov/

13. http://www.eeoc.gov/press/9-19-00.html

14. http://www.farmworkers.org/bracerop.html

15. http://www.needham.mec.edu/high_school/cur/kane98/kane_p3_immig/China/china.html

16. http://www.southbendtribune.com/99/apr/043099/local_ar/180051.htm

A special thanks to Vickie Rehkopf. 